\title{
Study on Local Application-Oriented Undergraduate Education of Intangible Cultural Heritage Inheritance
}

\author{
Jian $\operatorname{Lin}^{1, *}$ \\ ${ }^{1}$ Tan Siu Lin Business School, Quanzhou Normal University, Quanzhou, Fujian 362000, China \\ "Corresponding author.Email: 15652473@qq.com
}

\begin{abstract}
Intangible cultural heritage is the important mission of local application-oriented undergraduate education. The local application-oriented undergraduate colleges are not only the training base of intangible cultural heritage, but also the promotion force of intangible cultural heritage industrialization. Based on the analysis of the difficulties faced by the intangible cultural heritage education, such as the discipline system, the teaching resources, and active atmosphere, this paper puts forward the discipline system, the double teachers' team, the inheritance platform and the students' community to realize the integration goal of the local application-oriented undergraduate education and the inheritance of intangible cultural heritage.
\end{abstract}

\section{Keywords: intangible cultural heritage, application-oriented undergraduate, intangible cultural heritage}

education

\section{INTRODUCTION}

Intangible cultural heritage is the treasure of the continuation and development of human civilization. intangible cultural heritage protection, inheritance and innovation have become the strategic problems facing the whole world. In October 2003, "the Convention on the Protection of Intangible Cultural Heritage", promulgated by the United Nations, proposed "teaching knowledge of intangible cultural heritage in institutions of higher learning, promoting interdisciplinary scientific, technological and artistic research activities, and developing research methods". Intangible cultural heritage education has gradually become a new mission of modern universities [1]. In March 2017, the "China Traditional Arts and Crafts Revitalization Plan", led by the Ministry of Culture, also explicitly proposed "supporting qualified colleges and universities to set up relevant majors and courses in traditional arts and crafts, so as to train technical and theoretical research talents in traditional arts and crafts". Local applicationoriented undergraduate course is an important position of higher education service innovation-driven development. The implementation of intangible cultural heritage education can not only play the main role of cultural inheritance and innovation, but also serve the local economic and social development [2].

\section{LITERATURE REVIEWS}

With the promulgation of the "Convention on

CLC number: F406; Document code: A
Intangible Cultural Heritage", foreign countries are paying more and more attention to and investing in intangible cultural heritage education. French universities strictly follow the principles and objectives of the "Convention", take the employment market as the guide, and adopt the two modes of setting up professional degree majors and setting up independent courses "principal and auxiliary" to cultivate intangible cultural heritage talents (Blandishment-Gimblett, 2013) [3]. With its strong economic power, the United States launched the Public Archaeological Education Program as early as in the 1970s, which has highlighted the important role of universities in the fields of liberal arts research and digital protection (Bunten, 2008) [4]. Japan takes the popularization of children as the starting point. The combination of intangible cultural heritage and compulsory education and the all-round publicity let the intangible cultural heritage culture permeate every corner of whole people's life (Landorf \& Chris, 2009) [5].

China's intangible cultural heritage education originates from the public's appeal to the cultural expression of Chinese traditional way of life, and universities play the three functions - cultural heritage cultivation, scientific research and social service (Liu Chang and Yan Huo, 2018) [6]. In recent years, through the "intangible cultural heritage into the campus" activities, China has quietly promoted the students to produce cultural identity. From the initial viewing, appreciation has gradually moved to the inheritance of skills. The participation of students in the promotion and the relationship between non-genetic inheritors has 
gradually gone deeper (Chen Siqi and Li Yuzhu, 2018). Local applied undergraduate courses are characterized by the flexibility of professional setting, the diversity of teachers' structure, the guidance of educational practice, and the inevitability of talent training cooperation education (Chen Xiaohu and Yang Xiang, 2013) [2]. Based on the cooperation between schools and enterprises and the oral teaching of teachers, the modern education mode that mainly focuses on the cultivation of students' skills should become the main path for the protection and inheritance of intangible cultural heritage.

\section{DIFFICULTY AND DILEMMA: AN ANALYSIS OF THE PRESENT SITUATION OF THE INHERITANCE OF INTANGIBLE CULTURAL HERITAGE EDUCATION}

Education, as the main means of inheriting human culture, has its unique advantages. Based on the integration of educational resources and cultural resources, intangible cultural heritage education refers to the educational, teaching, scientific research and practical activities related to the integration of educational resources and cultural resources in a purposeful, planned and organized way, so as to realize the goals of cultural identity, skill inheritance and related compound talents training. In 2002, the first seminar on education and teaching of intangible cultural heritage in Chinese colleges and universities formally issued the "Declaration on Education of Intangible Cultural Heritage". For more than 10 years, the integration of intangible cultural heritage and higher education has been expanding in depth and breadth, but there are still many difficulties need to be solved. [7]

\section{A. The discipline system has not yet been established}

In 2006, China officially launched the review of national intangible cultural heritage representative catalogue inheritors. This work has also become an important part of the intangible cultural heritage curriculum system in universities. In October of 2006, the book "Introduction to Intangible Cultural Heritage", edited by Wang Wenwen of the Chinese Academy of Art, became the first textbook for intangible cultural heritage courses in China, which was widely used and played an important role in theoretical research and even universal education of intangible cultural heritage subjects. [7] In a long period of time, academia and intangible cultural heritage related courses, and even teaching materials are mainly used for reference. However, the early textbooks mainly focus on the macro-level of intangible cultural heritage protection and management. The introduction of intangible cultural heritage theory, especially the practice of micro-level is less discussed, which leads to the deficiency of the existing intangible cultural heritage curriculum. In recent years, although scholars of different disciplines have carried out more research and teaching practice on intangible cultural heritage from their own professional point of view, they have focused more on the field of art and folklore, or set up intangible cultural heritage-related elective courses in the major of liberal arts of well-known comprehensive universities in China, and the scientific macrointangible cultural heritage discipline system has not been established. The popularization of intangible cultural heritage education is difficult to get effective guidance and support.

\section{B. Inadequate teaching resources}

Teachers are the guarantee of the quality of intangible cultural heritage education. A typical characteristic of intangible cultural heritage is that a large number of teachers and students follow the traditional model of oral instruction. It is difficult to effectively graft and condense with the modern higher education system in the field of intangible cultural heritage education, especially the establishment of intangible cultural heritage inheritors and teachers of intangible cultural heritage-related courses in colleges and universities. Judging from the existing intangible cultural heritage group, most of them are old craftsmen with exquisite craftsmanship and profound culture. According to the data analysis of the fifth batch of intangible cultural heritage representatives published by the state, the average age of the inheritors reached 63 years old, and the proportion over 60 years old was nearly $60 \%$. To some extent, the factor of age restricts the inheritor's cognition of social development and the acceptance of new things. The inherent thinking makes the cooperation between college and intangible cultural heritage-inheritor having great uncertainty. According to the investigation of the related peer colleges and universities, even though there are many cases of inheritors entering the campus to give lectures and practice teaching which gained popularity among teachers and students, the mode of cooperation is still loose. Especially the mode relating to the existing intangible cultural heritage professional teachers in colleges and universities, the degree of integration is low, and the identity, concept, and cognitive conflict are frequent. Planning, implementation and evaluation of intangible cultural heritage theory and practice teaching are in the exploratory stage, and the overall teacher structure and resources are relatively weak.

\section{The active atmosphere is easy to distort}

The active atmosphere of inheriting culture is the basic principle of intangible cultural heritage protection. In practice, the active display of intangible cultural heritage education is often limited by the need of educational boundaries. In terms of intangible cultural heritage folklore, most of the intangible cultural 
heritage projects are closely related to the local national culture, people's life and folk religion, expressing special emotional sustenance and artistic value. Although it is one of the missions of colleges and universities to advocate the involvement in the production and life process of society, it is inevitable to filter out the elements related to religious belief when introducing intangible cultural heritage projects. The connotation of intangible cultural heritage becomes fragmentary. From the technical nature of the intangible cultural heritage, the intangible cultural heritage technology rooted in the folk, and was inseparable from nature. The reality of traditional crafts from the planting and selection of raw materials to processing and making into a device is difficult to be embodied in the classroom alone. Existing intangible cultural heritage demonstration teaching often takes a certain part, while the majority of teaching works are just the performance. It is difficult to truly present the integrity of intangible cultural heritage skills, the students' experience degree is not enough, and the teaching effect is not obvious. Thankfully, the wide application of digital technology to some extent makes up for the above-mentioned deficiencies, which provides a guarantee for the integrity of intangible cultural heritage classrooms in colleges and universities, and brings new problems to the balance of intangible cultural heritage digitization and activation.

\section{COUPLING AND FUSION: THE RELATIONSHIP BETWEEN INTANGIBLE CULTURAL HERITAGE INHERITANCE AND LOCAL APPLIED-ORIENTATION UNDERGRADUATE EDUCATION}

In October 2015, the Ministry of Education and other departments jointly issued the "Guiding Opinions on Guiding the Transformation of Some Local Ordinary Undergraduate Colleges to Application-oriented Universities." According to requirements, local application-oriented undergraduates have a solid theoretical foundation for local cultivation, higher professional technology applications and higher research capabilities. There are high-level applicationoriented, compound and innovative talents facing the front line of production [8]. Local application-oriented undergraduate education is the transformation of higher education to adapt to the new normal of economy. It has obvious characteristics of regionality and application, and has similarities with the attribute of "intangible cultural heritage".

\section{A. Intangible cultural heritage inheritance is the key content of local application-oriented undergraduate education}

At present, intangible cultural heritage projects at all levels are mainly scattered in prefectures or towns, and most of the places where local application-oriented undergraduate colleges and universities are located are prefecture-level cities, which are closely related to the origin of intangible cultural heritage, and the schools have strong local cultural characteristics from the day they were founded. The students mainly come from local and surrounding areas, with high cultural identities. Taking Quanzhou, where the author's office is located, as an example, there are 4 world-class intangible cultural heritages, 31 state-level intangible cultural heritages and 60 provincial-level intangible cultural heritages, forming a intangible cultural heritage ecological cultural circle with the characteristics of "sea silk". Abundant and high-quality intangible cultural heritage resources can not only provide support for applied talents' humanistic quality education, enhance students' national cultural identity and build cultural self-confidence, but also provide an important way to highlight the characteristics of the school. In addition, intangible cultural heritage is the wisdom of the working people in the practice of life handed down from generation to generation. Active atmosphere and sustainable development cannot be separated from innovation. Local application-oriented undergraduate colleges are an important position to carry out innovation and entrepreneurship education. The introduction of intangible cultural heritage resources into university campuses and the dissemination and scientific research of intangible cultural heritage skills also play a positive role in the cultivation and promotion of students' innovative consciousness, entrepreneurial thinking and creative ability.

\section{B. Local applied undergraduate colleges and universities are important bases for the cultivation of intangible cultural heritage talents}

Local application-oriented undergraduate education is different from traditional higher vocational education in that it emphasizes skills rather than scientific research, and it is different from research-oriented university. More emphasis is placed on the profession and application of talent training, that is, the balance between professional adaptability and research application. At present, a prominent problem faced by intangible cultural heritage is the aging of the representative inheritors and the lack of innovation power. The lack of recognition of the traditional culture and the unoptimistic prospect of the expected benefit of culture and economy lead to the lack of successors of many intangible cultural heritage projects and even lead to the phenomenon of "the extinction of human beings". Application-oriented undergraduate colleges are rooted in local areas, closely related to industry, and have rich experience in application-oriented talents training. For example, Quanzhou Normal University established School of Quanzhou Nanyin. Taking Nanyin's talent supply reform as a breakthrough, the school has 
vigorously carried out school-enterprise cooperation, especially the outstanding research capabilities in Nanyin's technical principles, laws, and industry and market docking, which has achieved precise docking for industry-university-research. Therefore, the application-oriented undergraduate universities should also become the important base and cradle of local intangible cultural heritage talents training scale and standardization.

\section{Local applied undergraduate colleges are the promotion force of intangible cultural heritage industrialization}

Through the market development and industrialization of intangible cultural heritage resources to achieve the protection and inheritance of intangible cultural heritage has been widely recognized by the academic community and the industry. [9] The industrialization of intangible cultural heritage is often confronted with difficulties because of its non-relic attribute and cultural protection. Colleges and universities can provide the support of manpower, field, intelligence and other advantageous resources for the industrialization of intangible cultural heritage. The industrial advantage of application-oriented undergraduate colleges to carry out intangible cultural heritage education is reflected in two aspects. First, the government should step up its support. For example, during the "13th Five-Year Plan" period, China invested 100 million yuan of special funds for each application-oriented university, which was used for the integration of production and education in universities and for the construction of cooperative education programs. Many provinces and local governments in economically developed areas have also allocated special funds for the construction of applied-technology colleges and universities. Specific to the construction of non-genetic inheritance bases in colleges and universities, support was also given in terms of funding, topics, platforms, and policies. Second, the attention should be paid on serving the local economy. One of the characteristics of local application-oriented undergraduate is the oriented application and open flexibility of professional setting, which can combine the setting of intangible cultural heritage major with the regional economic and social development closely, especially combine with universities which own more students' innovation and entrepreneurship bases, production and education integration training bases, etc., to provide a support platform for the marketoriented development, design and sales of intangible cultural heritage products.

\section{DIRECTION AND METHOD: THE IMPLEMENTATION PATH OF LOCAL APPLIED UNDERGRADUATE EDUCATION TO INHERIT THE INTANGIBLE CULTURAL HERITAGE}

The implementation of intangible cultural heritage education is a complicated systematic project. The local applied undergraduate colleges play an important role in the intangible cultural heritage protection and inheritance, and those colleges are the main force for the implementation of intangible cultural heritage education in colleges and universities. Only by actively exploring a set of effective operation methods and implementation paths can we promote the construction of an intangible cultural heritage talent training system and give full play to the functional role of local application-oriented universities in serving regional economic, social and cultural development.

\section{A. Setting up educational goals and constructing discipline system}

The intangible cultural heritage goal of applicationoriented undergraduate education is to promote the combination of application-oriented talents training and intangible cultural heritage, and to provide strong talent support for inheritance, innovation, research and management of intangible cultural heritage. [7] The research and training program of the Ministry of Culture and the Ministry of Education on heritage inheritors provide a directive idea and method for the construction of non-inherited discipline system in local application-oriented colleges and universities. Local colleges and universities can rely on the special cultural heritage resources to increase the learning content of regional cultural projects in the talent training program. They can also shape students' responsibility and consciousness of serving the local areas, protecting and inheriting the local intangible cultural heritage. At the same time, by giving full play to the advantages of the original disciplines in colleges and universities, we advocate the establishment of interdisciplinary nonlegacy colleges in colleges and universities, the establishment of non-legacy compulsory courses or professional elective courses, and the establishment of the non-legacy discipline system.

Taking Chongqing College of Arts and Sciences as an example, it is the first university in China to offer "Introduction to Intangible Cultural Heritage" courses to undergraduates. Through more than 10 years of course introduction practice, it has now formed three intangible cultural heritage curriculum systems: theoretical curriculum, transmission curriculum and expansion curriculum. Especially, the "students' hometown intangible cultural heritage project" is integrated into the course teaching practice. [10] In addition, Zhejiang Institute of Science and Technology included bamboo knitting skills as a separate subject in 
the talent training program of Wenchuang, and based on this, the college set up a specific curriculum catalogue, and jointly compiled school-based teaching materials with the inheritors, so as to ensure the realization of educational goals with abundant types of curriculum.

\section{B. Introducing folk artists to create a double-division team}

Double teachers are the undertaker of applicationoriented talents training. The connotation of double teachers includes two aspects, one is the diversification of business composition - both academic, technical and practical types; the other is the diversification of sources and it is not limited to universities, research institutes, and a considerable number of teachers with industry experience. [2] Adding intangible cultural heritage inheritors with unique skills in folk arts to the teacher team is the first step in building a intangible cultural heritage dual teacher team. This kind of cooperation can be loose or tight. The purpose is to give full play to the master's technical advantage and driving role, focusing on the cultivation of students' humanistic accomplishment and artistic creation ability. In addition, the school also has a plan to cultivate and introduce a group of professional teachers who love traditional culture and are committed to intangible cultural heritage, so as to expand the scale of teachers. At the same time, universities and colleges should do a good job planning, use expert lectures, field surveys, field study and other methods to strengthen the interaction between the dual teachers, thus effectively promote the healthy development of the intangible cultural heritage teacher community.

Taking Lingnan Normal University as an example, the school has set up intangible cultural heritage master studios such as embroidery, printing and dyeing. In addition to conducting lectures, skills learning and course teaching, it also includes co-creation with the school's characteristic professional clothing and visual art design, which has effectively explored the new idea of the integration of traditional intangible heritage and modern science and technology and has realized the living inheritance and creative transformation of intangible heritage.

\section{Establishing an inheritance platform and optimizing the teaching and research model}

In order to promote the all-round integration of Chinese excellent traditional culture into university education, the Ministry of Education launched the construction of traditional cultural heritage bases relative to local undergraduate universities in 2018. The bases dedicated to the popularization, protection, inheritance, scientific research and communication of cultural education. In addition to vigorously carry out intangible cultural heritage into the campus, the school should also go out, and cooperate with local governments and cultural institutions to establish an intangible cultural heritage education and research platform in a regional intangible cultural heritage area as a resource support for the transformation of intangible cultural heritage exercises, student training, and teacher research. On the one hand, making use of the intellectual and market-oriented advantages of the university's entrepreneurship park and science and technology park, it will form a regional alliance of intangible cultural heritage production, learning and research, and do a good job of the innovation and incubation support of inheritors and students' intangible cultural heritage projects, so as to realize the effective transformation of works into products and commodities. On the other hand, on the premise of doing well the basic theory research, the academic research achievement should be applied in the areas of management suggestion and decision-making basis for the local government and related departments, industrial development, intangible cultural heritage and so on.

For example, the "Museum of Folklore", cofounded by Wenzhou University and local government, is a paradigm. The museum not only provides resources for the school to carry out intangible cultural heritage practice teaching, but also promotes the protection and dissemination of local culture and the promotion of the school's influence. For another example, Tianjin University of Technology textile intangible cultural heritage research institute extends the cooperation of intangible cultural heritage education from the government to the industry and enterprise level.

\section{Relying on student associations to develop cultural services}

College students are the latent power of intangible cultural heritage. Relying on student associations to expand the function of cultural heritage service is an effective way to popularize intangible cultural heritage education. First of all, it advocates the establishment of a Chinese society or a specialized intangible cultural heritage society, incorporating tea art, Han clothes, poetry, calligraphy and painting, and folk art forms, etc., so that students can feel the unique charm and profound connotation of traditional culture, which can raise college students' attention and recognition of intangible heritage. Secondly, universities should rely on their innovation and entrepreneurship education (colleges), carry out innovation and entrepreneurship activities such as creative design of intangible cultural heritage products, business planning competitions, etc., to allow creative integration of intangible cultural heritage and professional learning. Thirdly, universities should enrich the field of intangible cultural heritage exchanges, and carry out training, consulting, 
performances, volunteering and other services in the form of walking into the community and walking into cultural halls.

For example, "Yangtze River intangible cultural heritage Society" of Yangtze University, founded in 2009, made college students understand and love intangible cultural heritage through academic lectures, art exhibitions, fieldwork, and home culture exhibition. In addition, East China Normal University's "Folklore Society on the Sea" focuses more on academic research, the inheritance of traditional Chinese festivals on campus, and advocates the establishment of a college non-hereditary practice student association, bringing the intangible cultural heritage community model to a more standardized, systematic operation. It has gradually become an indispensable force for universities to carry out intangible cultural heritage education [7].

\section{CONCLUSION}

Intangible cultural heritage inheritance has just begun in China, and the implementation of intangible cultural heritage education in colleges and universities is still in the exploration stage. Local applicationoriented colleges have significant advantages in intangible cultural heritage protection and inheritance. However, it must not be overlooked that intangible cultural heritage inheritance is a long-term and arduous undertaking. It is not enough to rely solely on the strength of education. It is necessary to stand at the strategic level of the country and cooperate with the government, enterprises, universities and scientific research institutions. From the perspectives of national policy, environmental construction, legal system, education reform, and industrial development, a more comprehensive and systematic operation method and implementation path will be explored.

\section{References}

[1] Du Lili. The Protection of Intangible Cultural Heritage as a New Mission of Higher Education: Taking French universities as an Example[J]. Modern University Education. 2016 (03): 45-51. (in Chinese)

[2] Chen Xiaohu, Yang Xiang. 14 Basic Issues for the Development of New Application-oriented Undergraduate Colleges[J]. China University Teaching. 2013 (01): 17-22. (in Chinese)

[3] Kirshenblatt-Gimblett, B. Intangible Heritage as Metacultural Production[J]. Problems of Museology. 2013, 56(1): 52-65.

[4] Bunten, Alexis C. Sharing Culture or Selling Out? Developing the Commodified Persona in the Heritage Industry[J]. American Ethnologist. 2008, 35(3): 380-395.

[5] Landorf C. A. Framework for Sustainable Heritage Management: A Study of UK Industrial Heritage Sites[J]. International Journal of Heritage Studies. 2009, 15(6): 494-510.

[6] Liu Chang, Yan Huoqi. On University's Organization and Institutional Support for the Inheritance of 'Negative
Heritage'[J]. Jiangsu Higher Education. 2018 (05): 79-82. (in Chinese)

[7] Sun Zhengguo. The practical Form of "intangible cultural heritage" Inheritance in Chinese Universities for More Than Ten Years[J]. Cultural Heritage. 2017 (01): 11-16. (in Chinese)

[8] Pan Maoyuan. What Is an Applied Undergraduate?[J]. Higher Education Exploration. 2010 (1): 10-11. (in Chinese)

[9] Huang Yonglin, Ji Mingming. On the Creative Transformation and Innovative Development of Intangible Cultural Heritage Resources in the Cultural Industry[J]. Journal of Huazhong Normal University (Humanities and Social Sciences). 2018, 57 (03): 72-80. (in Chinese)

[10] Mu Yanlin, Tan Hong, Wang Tianxiang, et al. Inheritance of Intangible Cultural Heritage Education: a New Approach to Cultural Quality Education in Contemporary Colleges and Universities - Taking Chongqing University of Arts and Science as an Example[J]. Studies in Ethnic Arts. 2011, 24 (01): 90-94. (in Chinese) 